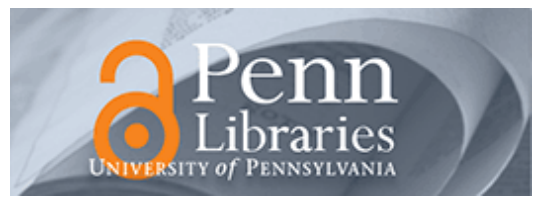

University of Pennsylvania ScholarlyCommons

September 1997

\title{
Denotationally cued interactional events: A special case
}

\author{
Stanton Wortham \\ University of Pennsylvania, stanton.wortham@bc.edu
}

Follow this and additional works at: https://repository.upenn.edu/gse_pubs

\author{
Recommended Citation \\ Wortham, S. (1997). Denotationally cued interactional events: A special case. Retrieved from \\ https://repository.upenn.edu/gse_pubs/106
}

Reprinted from Semiotica, Volume 114, Issues 3/4, 1997, pages 295-317. Publisher URL: http://www.atyponlink.com/WDG/loi/semi

NOTE: At the time of publication, author Stanton Wortham was affiliated with Bates College. Currently June 2007, he is a faculty member in the Graduate School of Education at the University of Pennsylvania.

We have contacted the publisher regarding the deposit of this paper in ScholarlyCommons@Penn. No response has been received.

This paper is posted at ScholarlyCommons. https://repository.upenn.edu/gse_pubs/106

For more information, please contact repository@pobox.upenn.edu. 


\title{
Denotationally cued interactional events: A special case
}

\author{
Abstract \\ Modern analyses of language use have come to focus as much on what we do with language as on what \\ we say with it (e.g., Austin 1975 [1956]; Goffman 1974; Gumperz and Hymes 1972; Searle 1969; \\ Wittgenstein 1953). With this shift to studying language's interactional functions has come an apparently \\ simple question: how does a stretch of talk come to count as a particular type of interactional event? \\ Answers to this question relied at first on the denotational functions of language. In the prototypical \\ cases presented by Austin (1975 [1956]), an utterance signals an interactional event through the \\ denotational value of certain predicating formulae. Uttered in appropriate circumstances, I promise both \\ denotes and accomplishes a speech act.

\section{Comments} \\ Reprinted from Semiotica, Volume 114, Issues 3/4, 1997, pages 295-317. Publisher URL: \\ http://www.atypon-link.com/WDG/loi/semi \\ NOTE: At the time of publication, author Stanton Wortham was affiliated with Bates College. Currently \\ June 2007, he is a faculty member in the Graduate School of Education at the University of Pennsylvania. \\ We have contacted the publisher regarding the deposit of this paper in ScholarlyCommons@Penn. No \\ response has been received.
}




\section{SEMIOTILA}

JOURNAL OF THE' INTERNATIONAL ASSOCIATION FOR SEMIOTIC STUDIES

REVUE DE L'ASSOCIATION INTERNATIONALE DE, SÉMIOTIQUE

\section{Editor-in-Chief/Rédacteur en Chef THOMAS A. SEBEOK}

\section{Offprint/Tiré à part}

\section{Mouton de Gruyter Berlin - New York}

\section{Denotationally cued interactional events: A special case ${ }^{1}$}

STANTON E. F. WORTHAM

Modern analyses of language use have come to focus as much on what we do with language as on what we say with it (e.g., Austin 1975 [1956]; Goffman 1974; Gumperz and Hymes 1972; Searle 1969; Wittgenstein 1953). With this shift to studying language's interactional functions has come an apparently simple question: how does a stretch of talk come to count as a particular type of interactional event? Answers to this question relied at first on the denotational functions of language. In the prototypical cases presented by Austin (1975 [1956]), an utterance signals an interactional event through the denotational value of certain predicating formulae. Uttered in appropriate circumstances, $I$ promise both denotes and accomplishes a speech act.

Contemporary accounts of verbal interaction have moved beyond this early insight, and now focus less on denotational values and more on indexicals (Silverstein 1976) or 'contextualization cues' (Gumperz 1982). We have learned that, in general, the denotational value of an utterance does not directly establish an interactional event (Levinson 1981). Austin's predicating formulae are special cases (Verschueren 1995). Although we do not yet have a fully adequate account of how linguistic cues signal interactional events, we do know that interactional effects result from the complex coordination of various cues, including nondenotational ones (Silverstein 1992).

This article reports on one type of speech event - 'participant examples ${ }^{2}$ - in order to explore more deeply how speakers use language to cue interactional events. In a participant example, participating individuals get cast as characters in an example. These participants then have two roles: as a character in the example and as a participant in the conversation. In some cases, as described below, participants act out the roles given to them as referents in the example. That is, speakers themselves come to act like the characters they have been assigned through the example. If John has said to Mary, 'let's assume I'm a master and you're a slave' - perhaps adopting this hypothetical case in an atternpt 
to understand a text better - John himself might start acting tyrannically, and Mary submissively. In such a case, John and Mary would be acting out their roles in the participant example. Based on sustained study of classroom examples, we know that such enactment happens more than one might expect (Wortham 1994).

When speakers enact a participant example, the denotational content of the example comes to organize the interaction. What John and Mary have described as the content of the example also becomes a description - perhaps even a script - for their own interaction. Note the similarity here between enacted participant examples and Austin's predicating formulae (like I promise). In both cases the denotational content of an utterance seems to identify and perhaps establish its interactional effect.

Participant examples do not describe what they enact as routinely and unproblematically as the predicating formulae identified by Austin. As described below, speakers also rely on nondenotational cues when they enact participant examples. Nonetheless, enacted participant examples and predicating formulae like I promise are both special cases - in that their denotational value describes their interactional function. Of course, even in such special cases, denotational content does not suffice to determine verbal action. Other cues can always lead participants to reconstrue the interactional event. But, other things being equal, in these special cases denotational content lays out a conversation's interactional organization.

This article explores the special case of participant examples, to see what role denotational and nondenotational cues play in signaling utterances' interactional effects. It turns out that the complexity of this type of speech event gives us grounds to suspect universal theories of linguistic action. The first section below reviews theories of linguistic action. The second section describes participant examples' structure. The third section explains how one type of linguistic form - personal pronouns - provides both denotational structure within the example and interactional structure for the conversation itself. The fourth section describes how, through the mediation of personal pronouns, the denotational content of participant examples can organize the speakers' interaction. The conclusion returns to the larger implications for theories of linguistic action.

\section{Framing linguistic action}

How does an utterance, or a group of utterances, identify a segment of conversation as a particular type of interactional event? Although substantial work on the interactional effects of language use was done earlier in the century (Havtánek 1955 [1932]; Vološinov 1986 [1973] [1929]), Austin (1975 [1956]) provides the most influential early theory of linguistic action. In his final formulation, Austin argues that every utterance has an 'illocutionary force', or a type of interactional function. In uttering a type of linguistic form in an appropriate context, a speaker follows the rule connecting that type of form to a certain illocutionary force, and thus the speaker performs a certain type of act.

Austin grounds his theory in the analysis of a particular kind of predication, which he calls 'explicit primary performatives'. This kind of usage has a peculiar property: the utterance denotes what it accomplishes, as in I promise. To determine the illocutionary force of the utterance, we can look at what it denotes. As Verschueren puts it, orthodox speech acts 'create a state of affairs in accordance with an expressed propositional content' (1995: 52). Despite Austin's attempt to move away from denotation as the central function of language, he focused on a special type of utterance in which the default denotational value in effect constitutes the
illocutionary force.

Austin accounts for illocutionary force by positing conventional rules that connect types of linguistic forms to types of actions. Searle (1969) exhaustively describes such a rule. The rule (1) identifies what type of sign indicates the act in question, and (2) describes features of the interactional context required for 'felicitous' - i.e., warranted and compelling - performance of the act.

It turns out to be crucial how a theory of linguistic action deals with context. According to speech act theory (i.e., Austin and Searle), some interactional context must be presupposed in order for an utterance to establish a particular type of interactional event. Certain contextual conditions must be present for the utterance to 'count as' a valid act. In the case of promising, for instance, the speaker cannot make a valid promise if she could never deliver the thing promised. In this way, speech act theory tries to explain how contextual conditions have a determinate effect on an utterance's interactional function.

Another early theory of verbal interaction comes from a very different tradition. Hymes (1972), an anthropological linguist, uses the construct of 'communicative competence' to reintroduce culture into the study of language. He argues that any utterance must be not only grammatically correct, but also culturally appropriate in the situation of use. That is, to be denotationally and/or interactionally successful, an utterance must fit the interactional and cultural context.

Hymes explains an utterance's cultural (in) appropriateness with rules that connect aspects of linguistic form to interactional effects - i.e., in 
this cultural context, this type of form counts as this type of act. He explicitly models these rules on grammatical competence: 'a linguistic sign is a relation between a linguistic form and a linguistic value. A sociolinguistic feature is a relation between a form and a sociolinguistic value' (Gumperz and Hymes 1972: 37). ' 'Value' is a technical linguistic term that denotes the distinctiveness of a particular form relative to the distribution of all other forms in the system. Saussure (1960 [1916]) claimed that the meaning of linguistic forms depends on and projects from their value in this sense.

Neither Hymes nor his co-editor Gumperz makes clear what sociolinguistic unit would be analogous to the phonological of morphologica! units used in formal analyses, or how such a sociolinguistic unit would distribute relative to a system. Nonetheless, they present their version of sociolinguistics as linguistically rigorous: 'a great deal of work can and must be done to identify the speech acts recognized in a community, work which is formal in the same sense as phonology and syntax' (Gumperz and Hymes 1972: 216).

This analogy with formal linguistics has an important consequence. It leads Hymes to propose 'competence-type' rules in order to explain linguistic action. Such rules say that a type of form counts as a type of act, given appropriate context. Note that these rules also specify contextual features that are prerequisite to the appropriate use of a linguistic form. Like Searle, who also worked in the shadow of Chomsky (1965), communicative competence researchers describe presupposed interactional context. Given a certain type of context, a certain type of form counts as a certain type of act.

Gumperz and Hymes, and those they have influenced in the 'ethnography of speaking' tradition (see the articles collected in Gumperz and Hymes [1972]; as well as, e.g., Au [1980]; Heath [1983]; Michaels [1981]; and Philips [1983]) do improve on Austin and Searle, however. Ethnographers of speaking give more accurate descriptions of culturally located interactional contexts. This empirical emphasis contrasts with Austin and Searle who, as Rosaldo (1982) points out disregard cultural differences in language use and rely on their own folk intuitions. The ethnographers of speaking also break with Austin's emphasis on predicating formulae that both denote and enact an event. They identify more subtle cues - in speech, prosody, and gesture - that signal an utterance's illocutionary force.

Nonetheless, because they rely on competence-type rules to explain interactional function, both speech act theorists and ethrographers of speaking give inadequate accounts. No account of linguistic action in terms of risles that merely specify presupposed context can explain what
Prague School linguists called 'foregrounding' (Havránek 1955 [1932]). Competence-type rules say that, given appropriate contextual features, an utterance containing certain cues or a certain type of form will count as a given type of act. However, as the Prague linguists pointed out, any such regularity can be flouted for interactional effect. Speakers often utter fonms in inappropriate contexts and thereby achieve definite effects. Someone who says to his or her main rival - in the midst of verbal jockeying at a group meeting - 'I love you', will most likely insult and not establish intimacy with the rival. Note that competence theories could explain why this utterance fails to establish intimacy (inappropriate context), but not how it insults.

Thus the analogy between interactionally effective and grammatical utterances breaks down. Violating a grammatical rule generates incorrect usage, but speakers often act contrary to pragmatic norms and successfully genetate interactional effects. The communicative competence theorist could propose a new rule for every effective flouting. But such an explanatory strategy gets awkward quickly, and it seems unlikely that people carry around rules covering all possible foregrounded usages. Furthermore, any theory of linguistic action that relies only on competence-type rules must be incomplete, because no matter how many rules are proposed the last one can always be flouted.

Contemporary critics of competence theories have reiterated this criticism, and added another (Goffman 1976; Levinson 1981). Appropriate forms can be uttered in apparently appropriate contexts, but yield unexpected results. Some aspect of a context unforeseen by the rule can always be made salient so as to negate or to transform the expected effect of an utterance. A new rule can be written to explain each exception, but this gets awkward quickly and can never be sufficient. An indefinite number of potentially relevant aspects of interactional context can be made salient in any case. This contextual indeterminacy means that theories which specify static presupposed contextual conditions cannot suffice, because such theories cannot explain how contextual features get highlighted in practice.

We make no scientific progress by simply pointing out the extendability of relevant context, however. As Goffman put it, we need 'to accumulate systematic understanding about contexts, not merely warnings that in another context, meaning could be different' (1976: 70). The arguments against competence theories do not mean that no form-context regularities exist. Any theory of language use must propose some rules that connect forms to effects, given presupposed context. But a theory that relies solely on such rules cannot explain creative language use. We need 
a theory of how speech contextualizes itself, of how it makes certain contextual features relevant in particular cases.

Silverstein (1976; 1992) and Gumperz (1982) begin to move toward such a theory. Silverstein (1976) was the first to lay out systematically the distinction between purposive functions of language - the level at which utterances establish types of interactional events, like teasing or referring - and the level of cueing. He analyzes cueing in terms of indexical functions - the use of linguistic forms to presuppose or create aspects of the context. Gumperz's concept of 'contextualization cues' is in some ways similar to Silverstein's indexical functions. A contextualization cue is an aspect of an utterance that indicates how its context should be construed. Hearers attend to cues in utterances, on this basis select certain aspects of the context as relevant, then infer what type of event the utterance is establishing.

This adds an internediate step between the utterance and the type of interactional event actually signaled. With competence-type rules, context matters only insofar as certain contextual features must be present for an utterance to count as a certain type of act. With indexical functions or contextualization cues, a construal of the context mediates between cues in the utterance and the event established. This intenmediate step allows two advances.

First, this type of theory can describe how language use not only presupposes, but also creates context (Sílverstein 1976). Sometimes utterances have interactional effects because, foregrounded, they themselves establish new aspects of the context, which in turn lead participants to infer that a different type of interactional event has been going on. This means that relevant context cannot be fixed by prior rules, because context cannot be fully described independent of the language use itself. Speech creates some aspects of its own context, and these created aspects can change the type of interactional event going on.

Second, this type of theory adds an inferential step that helps explain nonnormative results. Various aspects of any context might become salient and change the interactional function of a given utterance - even after it has occurred. This happens when nonnormative usage, or some salient aspect of the context, leads hearers to infer that the speaker is not using the utterance in the usual way. For instance: in the standard detective story, the hero, having been abducted, says something apparently innocuous on the phone to an ally - like 'you idiot, if it weren't for your horse fetish we wouldn't be in this mess'. The ally, knowing she has no horse fetish, infers that this is not a condemnation, but a clue that the hero is being held at the track
Gumperz's version of this inferential process relies on psychological processes: hearers infer, using procedures sketcher by Grice (1975), what actions speakers intend. Other theories of verbal inurartion try to avoid intentionalist psychology (Erickson and Schultz 1977; Heritage 1990-1991; Schegloff 1992; Silverstein 1992). Sucn theories try to reconstrue 'inference' and 'intention' in interactional terms. They describe how cues make certain aspects of context relevant, as those cues are taken up and established in the ongoing interaction. Silverstein (1992) provides the most comprehensive and promising nonintentionalist account to date.

Whether or not these interactional theories turn out to be successful in moving beyond psychological explanation, they add another aspect of linguistic action that must be examined - uptake. Indexicals or contextualization cues in an utterance often establish an interactional event because subsequent utterances indicate that those cues should be taken in a certain way. For a full account of language's interactional functions, then, we must examine how utterances are taken up into the ensuing action, and woven into the continuing, of discontinuous, fabric of the interaction' (Schegloff 1988: 131). An utterance's interactional effects depend in part on how it gets (re) contextualized by subsequent utterances.

Work clearly remains to be done in specifying the relationships among indexicals/contextualization cues, context, and the interactional events accomplished through speech. Nonetheless, we know too much now to go back to simpler accounts. Once a theory acknowledges the creative potential of language use and the indeterminacy of relevant context, it must explain how theoretically indeterminate context gets bounded in practice. Our question becomes: how does an interaction come to be a particular type of event - e.g., play instead of genuine dispute - when there are always verbal cues and aspects of the context that could signal another type of event? A full solution to this question will have to answer three subquestions: what aspects of utterances serve as cues? how do these cues make certain aspects of the context relevant? what types of inferential processes lead from relevant context to an established type of interactional event?

Answers to these three questions are beyond the scope of this article. But this brief review of research on linguistic action shows how far we have come from denotation-centered accounts. The denotational value of an utterance does not generally play the central role in establishing its interactional function. We should not, however, conclude that all speech events get signaled primarily by complex configurations of nondenotational cues. Most do. But denotational value does play a central role in some cases - like Austin's precticating formulae, and like participant 
examples. We need to look more closely at particular types of speech events before making general conclusions about linguistic action.

\section{Participant examples}

As mentioned above, conversations in which speakers discuss participarit examples can have a distinctive interactional pattern. The denotational content of a participant example can organize the interactional event that speakers are participating in. In such cases speakers themselves act out the roles and events they are discussing as the denoted content of the example. Exploring enacted participant examples will help us see more clearly how denotation can, in special cases, cue interactional events. This will, in tarn, give us greater insight into theories of linguistic action.

I came across the enactment of participant examples in a larger study of classroom example use. For this study I observed eight English and history classes, led by six different teachers, over three years. All classes were in one inner-city American public high school, with an ethnically mixed student body (about 50 percent black, 25 percent Hispanic, 15 percent white, and 10 percent Asian). I spent 128 hours in the school, observing classes and interviewing teachers, students, and adninistrators. In the final year I observed and audiotaped 81 class sessions, in one ninth-grade English class, one ninth-grade history class, and one twelfthgrade English class. The statistics and excerpts below come fron eight hours of transcribed conversation seiected from these 81 classes. For a report of the larger project, and for further details on the samples and the methodology, see Wortham (1994).

The following participant example occurred in one ninth-grade history class. The class has read Cicero's letter to Atticus, in which Cicero ponders what he should do about the tyranny of Caesar and the plot to overthrow him. Should he tefl Caesar? Should he join the plotters? Or should he just keep quiet? In this respect, the text describes a three-part inferactional structure in Rome: Caesar the tyrant, those plotting against him, and Cicero stuck between the two. The teacher (Mr. Smith, or T/S) places a student (Maurice, or MRC) in a hypothetical situation analogous to Cicero's, and asks him what he would do. ${ }^{3}$

T/S: Maurice let's give a good example, you'll love this. suppose this dictator, me. there was a plot going on. it's existing (3.0) among the peopie you knew. would you te:ll me. $(5.0)$
MRC: you said they know about it.

$\mathrm{T} / \mathrm{S}$ : the plotters, against me, they're planning to push me 155 down the stairs. $=$ and you know about it = hnhhahahaha

T/S: now we all know Maurice and I have ha(hh)d arguments all year. would you tell me about it

MRC: well- I might but uh what if they- what if they found 160 out that I told you then they want to kill me. (5.0) so I'mu putting myself in trouble to save you, and I'm not going to do it.

STS: hnh hahahaha

Denotationally, the example presents an interactional structure analogous to that in Rome: Mr. Smith-the-tyrant, the conspirators plotting to push him down the stairs, and Maurice-the-potential-infonmer stuck between the two. This is a participant example because some participants in the speech event itself (Mr. Stmith and Maurice) now have a second, interactionally relevant identity within the example.

Participant examples might, at first, seem no more interesting than any other kind of example. However, after exploring several aspects of participant and nonparticipant examples, I found a strong association between participant examples and 'denotational discontinuity'. Sometimes discussion of an example derails a conversation. In such a case speakers do not get back to the topic that led them into the example. Instead, they move out of the example into a new topic - often one inspired by the example. In such cases, the example leads to denotational discontinuity. I found the following distribution for participant examples and denotational discontinuity:

\begin{tabular}{r|c|c|}
\multicolumn{3}{c}{ CONTINUOUS DISCONTINUOUS } \\
\cline { 2 - 3 } PARTICIPANT & 80 & 31 \\
\cline { 2 - 3 } NONPARTICIPANT & 99 & 4 \\
\hline
\end{tabular}

From these data, it seems that participant examples are much more often associated with denotational discontinuity than nonparticipant examples. ${ }^{4}$ In analyzing specific participant examples, I discovered that the discontinuity often happens when participant examples generate interactional events that disrupt class discussion. Participant examples provide rich interactional resources and often lead to interactional activity. See 
Wortham (1994) for further analyses and examples to support this conclusion.

In the case of Mr. Smith-the-tyrant, for instance, the class starts out in a dispassionate discussion of whether Maurice-the-potential-informer should aid or oppose the tyrant. As we will see in more detail below, however, the class quickly falls into genuine conflicts between Mr. Smith and Maurice themselves, and between Maurice and several girls in the class. I claim that participant examples' structure facilitates these sorts of interactional events among participants.

A conceptual distinction from Jakobson (1971 [1957]) can help us better understand participant examples' structure, and their interactional richness. Jakobson distinguishes between the 'speech event' - the interaction among participants in a conversation — and the 'narrated event' what those participants are talking about. Because I use 'speech event', following Hymes (1972), to refer to a type of verbal interaction with a typical interactional structure - like narratives or participant examples - I will use 'narrating event' for Jakobson's 'speech event'. I mean 'narrate' here in a broad sense, to refer to all language use and not simply storytelling.

All speech talks about or denotes something, and all speech takes place in and contributes to some interaction. The linguistic forms actually uttered send messages about both narrating and narrated events. Speech about participant examples describes a particular type of narrated event: some actual or hypothetical event which includes at least one individual who is also participating in the narrating event. Those with a role in the example have two interactionally relevant identities: as a teacher or student in the classroom conversation (narrating), and as a character in the event described as the example (narrated). In the case introduced above, Mr. Smith has two roles - as dictator in the parrated event and as teacher in the narrating event - and so does Maurice - as potential informer (narrated) and as student (narrating)

Speech about participant examples often has important implications for interactional happenings in the narrating event. While discussing participants' characters in an example, speakers inevitably attribute certain social attributes to the (narrated) characters. Participant examples can have rich interactional implications because characteristics attributed to participants' characters in the example often have implications for those participants' interactional positions in the narrating event. For instance, exaggerating Mr. Smith-the-dictator's tyrannical characteristics, while discussing the example, may implicitly comment on Mr. Smith-theteacher — as a kind of double entendre or allegory about him. In this case, and others, such implicit commentary leads to further interactional jockeying among the participants themselves.

\section{Personal pronouns as mediators}

One type of linguistic form often plays a central role in participant examples' interactional effects - deictics. Deictics are forms like we, here, this, and now, the referential values of which are fixed only with respect to a particular narrating event. It turns out that deictics mediate between the denotational content of a participant example and its interactional effects. As the denotational description of a (narrated) participant example comes to have implications for particiants' own (narrating) interaction, deictics facilitate the process. To see how, we must understand deictics' structure.

Jakobson (1971 [1957]) provides a seminal account of deictics. Following Jespersen (1965 [1924]), he calls these linguistic forms 'shifters'. Shifters bridge the narrating event and the narrated event, because they depend on aspects of the narrating event to identify what they are saying about the narrated event. First and second person personal pronouns, for example, refer to individuals or groups and thus contribute denoted content to what the participants are talking about. But they successfully refer by pointing to some person or group that occupies a particular interactional role in the narrating event. $I$ refers by indexically pointing to the person speaking in the narrating event.

Jakobson and others study shifters because they establish that reference depends on context. Jakobson argued that shifters 'anchor' the referential content of a conversation -- the description of the narrated event - in the context of use. Such anchoring seems to be essential to the referential function of language in all kinds of conversation (Hanks 1990).

Others have explored shifters' role in the interactional functions of language use (Brown and Gilman 1960; Errington 1988; Silverstein 1976). As the backing or warrant for referring, shifters index a model of the narrating event. We, for example, refers to some set that includes the speaker and some other(s). Consummated use of we establishes reference to that set, thus contributing to the anchoring of the narrated event in the narrating one. It also entails a representation of the speaker's interactional role, by presenting her as a central or defining member of a certain interacting group. Thus shifters presuppose (or establish) interactional organization among participants, in the narrating event.

We can see this in the example of Mr. Smith and Maurice. In the short segment given previously, where Mr. Smith introduces the example, he 
and Maurice use personal pronouns to pick out the three interactional groups. Mr. Smith-the-tyrant is $I$ or you, depending on whether he or Maurice is speaking. Maurice-the-potential informer is you or $I$, and the conspirators are they. (As the example gets elaborated, other students in the class get assigned roles as conspirators within the example). Speakers continue to use these shifters to establish and maintain the boundaries between groups while discussing the example.

This set of personal pronouns is represented in Table 1 . In this notation, two forms separated by a slash have the same referent but are spoken by different people (i.e., Mr. Smith systematically opposes $I$, referring to himself, to you, referring to Maurice; and Maurice systematically opposes you, referring to $\mathrm{Mr}$. Smith, to $l$, referring to himself).

As represented iconically in Table 1, the pronouns here mediate between the participants and their narrated roles. In discussing the example, speakers use the pronouns to lay out and to maintain the three interactional groups. Because the same pronouns refer to the participants in both the narrated and narrating event, descriptions of the participant example can have implications for the speakers' own relationship. In talking about you, for instance - referring to Mr. Smith-the-tyrant Maurice can make veiled accusations about Mr. Smith-the-teacher.

It turns out that Maurice is motivated to do this. At line 157, Mr. Smith says 'now we all know Maurice and I have ha(hh)d arguments all year'. Priox to the example, everyone in the class, including myself as a regular observer, knows that Mr. Smith and Maurice have had a strained relationship. Mr. Smith holds students to a relatively rigid code of conduct, and Maurice has resisted this all year. Most other students acquiesce, withdraw sullenly, or misbehave in a teasing way. But Maurice's resistance seems more of a genuine struggle for power.

On this day, before class began, I overheard Maurice complaining to a friend. The night before, Mr. Smith had apparently told Maurice's parents that he has a 'bad attitude'. Maurice expresses his anger constructively, by participating actively in this class session. He does not

Table 1. Pronoums mapping participants' interactional positions

\begin{tabular}{|c|c|c|}
$\begin{array}{c}\text { Participants } \\
\text { (narrating) }\end{array}$ & $\begin{array}{c}\text { Personal } \\
\text { pronouns }\end{array}$ & $\begin{array}{c}\text { Example } \\
\text { (narrated) }\end{array}$ \\
\hline Mr. Smith & L/you & tyrant \\
\hline Maurice & you/I & informer \\
\hline Students & they & plotters \\
\hline
\end{tabular}

attack Mr. Smith, either intellectually or personally, but he tries hard to show the teacher that he understands the issues. My notes mention that he seems unusually intense and that he looks Mr. Smith directly in the eye when answering questions - with a look I characterized as 'wary and defiant'.

As shown in line 157, and also in his 'you'll love this' at line 148, $\mathrm{Mr}$. Smith recognizes his power struggle with Maurice. He mentions it at this point because he also recognizes that the (narrated) example may have implications for their (actual, narrating) relationship. It gives Maurice the opportunity, within the example, to express his anger at Mr. Smiththe-teacher. Maurice takes this opportunity, in places, by imagining that he would leave Mr. Smith-the-tyrant to be killed.

In doing this, Maurice takes advantage of his and Mr. Smith's dual roles, and the referential ambiguity of the personal pronouns. In talking about the example, he sends implicit messages about his actual relationship with $\mathrm{Mr}$. Smith. But it turns out that personal pronouns used in participant examples contribute more than referential ambiguity to the establishment of interactional events.

Personal pronouns often carry interactional presuppositions by being systematically juxtaposed with other personal pronouns. In the example, Mr. Smith uses I to refer to himself as a tyrant, you to refer to Maurice as a potential informer, and they to refer to the other students as conspirators. This opposition of l:you:they denotationally maps characters' positions within the example, and thus lays out interactional organization for both narrating and narrated events. Note that this opposition involves more than just the referential values of the pronouns. It presents a map of interactional organization because the shifters presuppose a certain interactional structure. Participants do not simply rely on the shifters' referential ambiguity to send implicit messages about other actual participants. They also use personal pronouns" more complex interactional presuppositions to map out structure for both narrated and narrating events. To see more clearly how, we must discuss the enactment of participant examples.

\section{Enacting participant examples}

Closer examination of participant examples reveals that they often spill into the narrating event in a particular, organized way. A configuration of roles attributed to participants' characters in the narrated event can get transferred onto the actual participants in the narrating event. The interactional organization described in the example organizes the 
narrating event, as participants act out their narrated roles. In the case of Mr. Smith-the-tyrant, for instance, Mr. Smith himself comes to act tyrannically, and Maurice gets stuck in the middle like Cicero. I have done detailed analyses of four extended discussions of participant examples, and each one involves enactment. See Wortham (1994) for analyses of these four cases.

Shifter usage plays a role in enactment. Prior to the introduction of a classroom participant example, speakers' use of personal pronouns separates the subject matter - the narrated content being discussed - from the narrating interaction. Participants use first and second person pronouns to refer to participants in the narrating event. Talk of this sort usually manages the interaction - as in 'what did you say?', 'I meant Cicero", etc. Participants use third person pronouns to refer to people in the subject matter. Before the example of Mr. Smith-the-tyrant gets introduced, participants call the Romans 'they' and Cicero 'he'.

With the introduction of a participant example, speakers distinguish two aspects of the narrated event. They refer to the subject matter, like Cicero and the Romans, in the third person as before. They generally refer to the characters in the participant example with first and second person pronouns. Mr. Smith-the-teacher, for example, refers to Mauricethe-potential-informer as you. Through their presuppositions about interactional organization, the pronouns map out the narrated event. Using $I$ to refer to Mr. Smith-the-tyrant, Mr. Smith asks Maurice-the-potentialinformer (you) whether he would take Mr. Smith-the-tyrant's side. Would Maurice-the-potential-informer become part of a we, with Mr. Smiththe-tyrant, or will he become part of they - the other students who are opposed to Mr. Smith-the-tyrant, as conspirators?

This interactional issue - which is described as the denotational content of the (narrated) example - becomes salient in the narrating event also. It becomes clear that $\mathrm{Mr}$. Smith-the-teacher would also like Maurice-the-student to side with him. In an enacted example, the interactional organization mapped out by shifters' presuppositions gets transferred onto the narrating event itself. Thus the interactional events in the classroom are cued in large part by the denotational content of the example. We can see this transfer occurring in the case of Mr. Smiththe-tyrant.

While discussing the example introduced above, Maurice gets put in the same interactional position that the text describes Cicero in: he rnust choose either to ally himself with those in power or to affiliate with the opposition. This position becomes uncomfortable for Maurice, as it was for Cicero. Maurice-the-potential-informer's decision not to tell $\mathrm{Mr}$.
Smith-the-tyrant about the plot has consequences for Maurice-thestudent. We can see this in the following segment:

T/S: well that was my next question, do you think Caesar was a yrant. $=$ do you think Cicero thought $=$

185 ST?: $\quad=$ I don't think so.

$\mathrm{T} / \mathrm{S}: \quad=$ Caesar was a tyrant

ST?: no

MRC: yes

T/S: then what's his problem. If the man- you just told me

190 point blank $\mid=$ that we could be pushed down stairs = MRC: =so.

$\mathrm{T} / \mathrm{S}: \quad=$ and you wouldn't feel a thing about it. what's his big deal, if he believes Caesar is a tyrant, so what.

195 . well- he- if $u: h$ he [ 4 syll ] that they're making some kind of plot against him, but he doesn't want to get involved. he doesn't know if he should get involved, he could get himself in more trouble. since he's already [ 3 syll ] =

200

T/S: well if Caesar's a tyrant why shouldn't you get involved. tyrants are generally dictatorial nasty people, that prevent peo:ple from being at their ease.

When Mr. Smith says 'you just told me point blank that we ${ }^{5}$ could be pushed down stairs and you wouldn't feel a thing about it' (lines 189-192), both the volume and tempo of his speech increase. He seems angry. Even though they are overtly speaking about the example, $\mathrm{Mr}$. Smith-the-teacher treats Maurice's choice not to tell him as a betrayal.

This starts to put the same sort of pressure on Maurice-the-student that was applied to Cicero and Maurice-the-potential-informer. Note that Maurice's characterization of Cicero's hesitation in the face of his dilemma (lines 194-198) could apply to Maurice-the-student's own situation. He can tell that his answer does not please Mr. Smith-the-teacher, but he does not know what to do about it. So Maurice-the-student begins to occupy Maurice-the-potential-informer's role, as it is described in the narrated event. In forcing Maurice-the-student into this position, $\mathrm{Mr}$. Smith-the-teacher also acts a bit tyrannically - thus acting out the narrating event in another respect.

At this point Mr. Smith may simply be play-acting to involve the students - although this probably does not change the fact that his behavior must seem tyrannical to Maurice. Maurice-the-student's 
problems become more serious, however, when several girls volunteer to tell the teachers about the plot.

$\mathrm{T} / \mathrm{S}:$

$\mathrm{T} / \mathrm{B}$ :

STS: right. I would ((* overlapping $\mid=$ comments *))

going to warn us though.

T/S: no.

T/B: what- what are you going to do that day Maurice. (1.0)

MRC: stay away. [ 2 syll]

$240 \mathrm{~T} / \mathrm{B}$ : what are you going to do?

MRC: I'm going to slay away so I won't be- be: =

T/B: so you're not going to come to school on Wednesday.

MRC: ${ }^{\circ} \mathrm{no}^{\circ}$

CAN: that way he's a coward.

245 ST?: what would you do

MRC: what would you do

T/S: a coward.

CAN: yeah 'cause he's scared.

At lines 233-234, Candace and then other female students affiliate with the teachers, within the example. This adds another interactional group in the narrated event - loyal subjects. Candace refers to this group using a personal pronoun opposition, as represented in Table 2.

When Candace, and then Mr. Smith, call Maurice a coward (lines 244 ff.), she begins to speak as Candace-the-student. Her energetic tone here indicates that she is not only elaborating the example, but also picking on Maurice-the-student. This establishes another group in the narrating interaction - Candace and the girls (several of whom subsequently join her cause) - who position themselves with respect to Maurice and the
Table 2. Pronouns mapping Maurice and Candace's positions

\begin{tabular}{|c|c|c|}
\multicolumn{1}{c}{$\begin{array}{c}\text { Participants } \\
\text { (narrating) }\end{array}$} & $\begin{array}{c}\text { Personal } \\
\text { pronouns }\end{array}$ & $\begin{array}{c}\text { Example } \\
\text { (narrated) }\end{array}$ \\
\hline $\begin{array}{c}\text { Mr. Smith } \\
\text { Mrs. Bailey }\end{array}$ & we/you & tyrants \\
\hline Candace & you/I & loyal subject \\
\hline Maurice & he & traitor \\
\hline
\end{tabular}

teachers. Like their characters in the example, in the classroom the girls affliate with the teachers and exclude Maurice.

Gender plays an interactional role here, as it has all year in this ninthgrade classroom. Girls and boys generally occupy separate, often antagonistic groups. Girls typically have more latitude to affiliate with teachers. Boys act more oppositionally toward teachers, and risk losing face if they do not.

Thus the girls have intensified Maurice-the-student's interactional predicament in the narrating event. He might like to affiliate with Mr. Smiththe-tyrant - and thus, implicitly, with Mr. Smith-the-teacher - since he has aroused Mr. Smith-the-teacher's anger by distancing himself. But to do so, he would have to affiliate with both the teachers and the girls. This would damage his standing with the other boys.

Like Maurice-the-potential-informer (and like Cicero), Maurice-thestudent gets excluded by the other groups as he thinks about what to do. We can see this exclusion in another pattern of pronoun usage. For most of the remaining discussion of the example, other speakers exclude Maurice from the conversation, by referring to him primarily as he. A closer look reveals that the teachers do continue to refer to Maurice as you in certain contexts. The shift from you to he and back establishes different organizations for the narrating interaction.

Maurice-the-student started out participating with the teachers in the discussion of the example. But immediately after Candace has said that she, unlike Maurice, would warn the teachers about the plot, Mrs. Bailey and some of the girls start to exclude Maurice - talking about him as he. (Note that they could have continued to refer to him as you, as they do with Mr. Smith and Candace.) This switch to he sends an interactional message: Maurice no longer belongs to the group that includes the teachers and female students in the narrating interaction. In both the narrated and narrating events, Maurice is caught on the outside. 
Mr. Smith in particular does on occasion turn back to Maurice and include him (as you), when trying to entice Maurice-the-potentialinformer to affiliate with the teachers. Maurice continues to hesitate, however. At the end of these interludes both students and teachers exclude him again, using he to refer to his character in their discussions of the example. After a few minutes Mr. Smith gives up on Maurice. In the following segment, although $\mathrm{Mr}$. Smith directly addresses Maurice as you, he speaks about Maurice-the-potential-informer's interactional position in the past tense - as if it has already been settled.

T/S: you told us you wouldn't tell us anything.

ST?: haha

ST?: 'I wouldn't."

T/S: you'd rather see our mangled bodies at the bottom of 365 the staircase.

MRC: I: told you I wouldn't be coming to school that day.

T/S: does that mean you're not part of the plot.

ST?: yeah

MRC: I'd still be part of it. I- $\mid=$ if I

$370 \mathrm{~T} / \mathrm{B}$ :

it =if you- if you know about

T/S: if you know about it that's: an accomplice. you knew about it. you could have stopped it. all you had to do is say - it shouldn't be done, it's wrong.

Here Mr. Smith accuses Maurice-the-potential-informer of wishing for the teachers' violent demise. At line 364, his colorful comment might be taken as a joke. But Maurice's tone at line 366 is quite earnest. In his comment at line 372, Mr. Smith's tone is angry again. And, by using the word 'accomplice' to refer to Maurice-the-potential informer, Mr. Smith casts Maurice's hypothetical character as morally questionable.

Within the example Maurice-the-potential-informer has made his decision, and this has consequences in the narrating event. After this segment, teachers and students consistently refer to Maurice as he for about six minutes. Maurice-the-student has been excluded from the teachers' and the girls' group. He can still be a member of the boys' group, but the other boys aimost never participate in class. So in joining that group he gives up on participating in classroom activity.

Thus Maurice-the-student acts out the dilemma confronted by Cicero and by Maurice-the-potential-informer. The description of the narrated event comes to organize the classroom interaction. Mr. Smith-the-teacher also plays the role of tyrant relatively well. Like a tyrant, he has the power to reward students if they behave properly and punish them if they do not. He uses this power to tyrannize Maurice-the-student, by forcing Maurice into a difficult situation and then excluding him. In this way the denotational topic of the classroom conversation, through the mediation of the participant example, takes over the interaction in which the example is discussed. Maurice-the-student gets caught in the middle, and $\mathrm{Mr}$. Smith-the-teacher acts somewhat like a tyrant. Interactional structure described in the text gets described in a participant example, then acted out in the narrating event.

With enacted participant examples, then, as with Austin's (1975 [1956]) explicit primary performatives, we can look to the denotational content of the talk in order to figure out its interactional force. Of course, explicit primary performatives' interactional force is more explicit, and more automatically takes effect. Only some participant examples get enacted, and their interactional message generally remains implicit. Furthermore, participant examples' interactional power does not reside in particular predicating formulae, but in a much more diffuse set of cues. Nonetheless, in some cases we can read much of the structure of the narrating event off of the denotational content of the example.

\section{Conclusion}

In the case of enacted participant examples, then, we can formulate a more specific answer to the question raised at the beginning. What cues signal that discussion of a participant example counts as a particular type of interactional event? We have seen that discussion of an enacted participant example becomes an identifable interactional event in large part because of the denotational content of the example. What participants describe as their roles and actions in the example comes to be the roles and actions taking place in the narrating conversation, among participants themselves. We have also seen that personal pronouns play a central role in this process, as they lay out the interactional organization of the narrated and then narrating events.

Three qualifications are in order here. First, we should not overemphasize the role of personal pronouns in establishing enacted participant examples' interactional effects. My analyses of participant examples focus on the use of personal pronouns because of the systematic presuppositions these shifters carry about participants' interactional positions in the narrating event. Any indexical, shifter or not, can potentially play an important role in signaling the interactional roles of participants discussing a participant example. The analysis above takes into account other 
indexical cues, as any adequate analysis must. But personal pronouns play a special role for this type of speech event. In a discussion of participant examples, personal pronouns usually provide the backbone of interactional organization for the narrating event.

Second, the denotational content of a participant example does no establish an interactional event automatically, in a simple mechanical way. Even in this special case, competence-type rules do not suffice to explain how interactional events get established through participant examples. Speakers accomplish their interaction, using the denotational organization of the example as a resource. We can see the contingent character of this framing process in the analysis above. Teachers and character of this frarich act out the example. They tailor the interactional structure of the example to ongoing interactional patterns in their classroom. Cicero, for instance, did not mention a group of loyal subjects in his description of Roman politics, but teachers and students add this group because it fits with the male/female interactional division in their classroom.

Third, as should also be clear from the example analysed above, Thitional cues do not suffice to indicate the interactional function of examples. The analysis relied on background information indexed by participants' speech, which was often not referred to explicitly. And it relicd centrally on personal pronouns' indexical presuppositions about interactional roles (for instance, teachers and students excluded Maurice through the indexical presuppositions of he, as systematically opposed to you). Nonetheless, more than in most speech events, the denotational content of an enacted participant example provides central cues in identifying what interactional event is going on.

The complexity and particularity of participant examples, as interactional resources, should give us pause when considering general theories of linguistic action. In general - as Goffman (1976), Gumperz (1982), Silversein $(8976,1992)$ and others have shown - we now know that Silverstein $(1976,1992)$ and othe central role in signaling an utterance's interactional function. But participant examples, when enacted, resemble Austin's explicit primary performatives, because in these types of speech event denotational cues do play a central role in signaling interactional function. In any particular case, of course, denotational cues can be overridden, and the example or primary performative can serve an unexpected interactional function. But this inevitable defeasibility does not change the general pattern for these denotationally cued interactional events.

We should not conclude that general theories of linguistic action serve no purpose. Clearly there have been important advances between Austin's early theory and contemporary ones, and these advances help us understand empirical cases. But in developing theories of linguistic action, we must attend more closely to particular types of speech events and their characteristic structures. A full theory will need to be contextualized in this way, in order to illuminate empirically occurring linguistic action.

\section{Appendix: Transcription conventions}

: $\quad$ for abrupt breaks, stops (if several, stammering)

'?' for rising intonation

$\because \quad$ for falling intonation

'ital.' (italics) for sitess

'CAPS' for heavy stress

(1.0) for silences, to the nearest second

" $=$ =' indicates simultaneous talk by two speakers

' ' interruption or next utterance following immediately, or contivuous talk represented on separate lines because of need to represent overlapping comment on intervening line

'[...]' doubtful transcription or conjecture

'(("...*)) transcriber comment

elongated vowel

$\therefore{ }^{\prime \prime} \quad$ segment quieter than surrounding talk

pause, breath without marked intonation

'(hh)' laughter breaking into words while speaking

\section{Notes}

l. I would like to thank Michael Silverstein for his substantial contributions to this research. I would also like to thank Aaron Cicourel, Douglas Glick, and Michael Locher for comments on an earlier draft, and the Spencer Foundation for supporting the initial write-up of the project.

2. Unspecified references to this edited volume are to the introductory paragrapts prefaced to each section by the two editors.

3. For transeription conventions, see the Appendix

4. Chi-square ( $\mathrm{d} f=1, N=2(4)=20.85(\mathrm{p} \leq .001)$. A cluster analysis showed that participant examples which lead to denotational discontinuity aiso tend to be analogies in their logical structure (as opposed to counterexamples or examples illustrating an established generalization), and they (end to be discussed for long periods of time. Participant examples represent more than one-third of the total number in this table because it includes the critire sample - both those classes selected randomly and those selected for a high density of participant examples. The general estimate given above - that about one in three examples is a participant example - comes only from the randomly selected sample, and is thus more likely to generalize.

5. Two teachers are running this class discussion, Mr. Smith and Mrs. Bailey. Several minutes earlier, Mrs. Bailey (or ' $T / B$ ') has included herself as a hypothetical tyrant in the example, along with Mr. Smith. Thus Mr. Snith uses we at line 190 to refer to the 
teachers-as-dictators. Adding Mrs. Bailey as a dictator complicates the narrating interaction in ways that go beyond the scope of this brief analysis (see Wortham [1994] for further details). I intend bere only to illustrate how participant examples get acted out, by focusing on Mr. Smith and Maurice.

\section{References}

Au, K. (1980). Participation structures in a reading lesson with Hawaijan children Anthropology and Education Quarterly 11, 91-115.

Austin, J. (1975 [1956]). How to Do Things with Words, second edition. Cambridge, MA Harvard University Press.

Brown, R. and Gilman, A. (1960). The pronouns of power and solidarity. In Style int Language, T. A. Sebeok (ed.), 253-276. Cambridge, MA: MIT Press.

Chomsy $N(1965)$. Aspects of the Theory of Syntax. Cambridge, MA: MIT Press

Erickson, F. and Schultz, J. (1977). When is a context? The Quarterly Newsletter of the Institute for Comparative Hunan Development $1,5-10$.

Errington, J. (1988). Struciure and Style in Javanese. Philadelphia: University of Pennsylyania Press.

Goffman, E. (1974). Frame Andysis. New York; Harper \& Row.

- (1976). Replies and responses. Language in Socieity 5, 257-313.

Grice, H. (1975). Logic and conversation. In Syntax and Semantics, P. Cole and J. Morgan (eds.), vol. 3, 41-58. New York: Academic Press.

Gumper J (1982) Discourse Strategies. New York. Cambridge University Press.

Gumperz, J. and Hymes, D. (1972). Directions in Sociolinguistics. New York: Basil Blackwell.

Hanks, W. (1990). Referential Practice. Chicago: University of Chicago Press.

Hayranek B. (1955 [1932]). The functional differentiation of the standard language, trans. by P. Garvin. In A Prague School Reader, P. Garvin (ed.), 1-18. Washington, DC: Washington Linguistics Club.

Heath, S. (1983). Ways with Words. New York: Cambridge University Press.

Heritage J (1990-1991). Intention, meaning and strategy. Research on Language and Social interaction 24, 311-332.

Hymes, D. (1972). Models of the interaction of language and social life. In Directions in Sociolintquistics, J. Gumperz and D. Hymes (eds.), 35-71. New York: Basil Blackwell.

Jakobson, R. (197! [1957]). Shifters, verbal calegories, and the Russian verb. In Selected Writings, R. Jakobson, vol. 2, 130-147. The Hague: Mouton.

Jespersen, O. (1965 [1924]). The Philosophy of Grammar. New York: W. W. Norton.

Levinson, S. (1981). The essential inadequacies of speech act models of dialogue. In Possibilaties and Linitations of Pragmatics, $H$. Parret, M. Sbisà, and J. Verschueren (eds.) 473-492. Amsterdam: John Benjamins.

Michaels, S. (1981). Shating time. Language in Society 10, 423-442.

Philips, S. (1983). The Invisible Cullure. New York: Longman.

Rosaldo M. (1982). The things we do with words. Language in Society 11, 203-237.

Saussure, F de (1960 [1916]). Cours de Linguistique Gérérale, fifth edition. Paris: Payot.

Schegle (1988) Goftman and the analysis of conversation. In Erying Gofman, P. Drew and A. Wootion (eds.), 89-135. Boston: Northeastern University Press.

- (1992). To Searle on conversation: A note in return. In (On) Searle on Conversation.

H. Parret and J. Verschueren (eds.), 113-128. Philadelphia: John Benjamins.
Searle, I. (1969). Speech Acts. New York: Cambridge University Press.

Silverstein, M. (1976). Shifters, linguistic categories, and cultura] description. In Meaning in Anthropology, K. Basso and $\mathrm{H}$. Selby (eds.), 11-55. Albuquerque: University of $\mathrm{New}$ Mexico Press.

-(1992). The indeterminacy of contextualization: When is enough enough? In The Contextualization of Language, A. DiLuzio and P. Auer (eds.), 55-75. Arasterdam: Jobn Benjamins.

Verschueren, J. (1995). Linguistic pragmatics and semiotics. Semiotica 104 (1/2), 45-65.

Vološinov, V. (1986 [1973] [19291). Marxism and the Philosophy of Language, trams. by L. Matejka and I. Titurik. Cambridge, MA: Harvard University Press.

Wittgenstein, L. (1953). Philosophical Investigations, trans. by G. E. M. Anscombe. Oxford: Blackwell.

Wortham, S. (1994). Acting Out Parcicipant Examples in the Classroom. Philadelphia: John Benjamins.

Stanton E. F. Wortham (b. 1963) is Assistant Professor at Bates College (swortham@bates. edu $\rangle$. His research interests include the intersection of cultural psychology, serniotics, and classroom discourse. He has previously published Acring Out Participant Examples in the Classroon (1994) 